\title{
Access to justice: An evaluation of the informal justice systems
}

\author{
Jawad Ahmad*| Georg Von Wangenheim \\ Institute for Economic Law, University of Kassel, Kassel, Hessen, Germany. \\ *Correspondence Emails: uk034815@student.uni-kassel.de | jawadazeez@gmail.com
}

\begin{abstract}
The judicial system of any state can be divided as formal and informal, where the formal is under the state (official) and informal may or may not be under the domain of the state (informal justice system). Since both systems provide access to justice, however, the informal system is viewed as a threat to formal justice system. In this context we need to better understand the role played by informal justices system. We have focused on three fundamental issues, first to evaluate the role of the alternate and informal justice system to improve access to justice. Second, we listed weaknesses in informal justice systems that gives us an insight into our third goal of suggesting a framework for engaging informal justice system and improved on its shortcomings which can be helpful in supporting or reducing the burden on the formal system.

Because of the absence of relevant literature, we resorted to empirical reports and case studies on other developing countries' to present our arguments. We showed that informal system is playing a positive role in the society and there is a need to reform the system especially for its negative traits, e.g., human rights.
\end{abstract}

\section{Article History}

Received:

November 30, 2020

Last Revised:

February 22, 2021

Accepted:

February 28, 2021

Published:

June 4, 2021

Keywords: informal justice system, panchayats, jirga, customs, culture, conflict management, arbitration, reconciliation, peace, dispute resolution.

JEL Classification: K1: basic areas of law, K4: legal system

\section{How to Cite:}

Ahmad, J., \& Wangenheim, G. V. (2021). Access to justice: An evaluation of the informal justice systems. Liberal Arts and Social Sciences International Journal (LASSIJ), 5(1), 228-244. https://doi.org/10.47264/idea.lassij/5.1.16

\section{Publisher's Note:}

IDEA PUBLISHERS (IDEA Journals Group) stands neutral with regard to the jurisdictional claims in the published maps and the institutional affiliations.

Copyright: () 2021 The Author(s), published by IDEA PUBLISHERS (IDEA Journals Group). This is an Open Access article published under the Creative Commons Attribution-NonCommercial 4.0 International License (http://creativecommons.org/licenses/by-nc/4.0/) 


\section{Introduction}

Traditionally it was believed that, there are three pillars of state, namely the legislature, the Executive, and the Judiciary. These three pillars uphold any state and ensure the working of a smooth democratic and legal government process (Vile, 1967). Out of the three, two are related to the legal fraternity and can shed a light on the importance of not only lawmaking, but to promulgate fair legal orders as well. The measure of this legal environment makes an important variable called "institutions", which can be measured through rule of law. It is defined by United Nations as "a principle of governance in which all persons, institutions and entities, public and private, including the State itself, are accountable to laws that are publicly promulgated, equally enforced and independently adjudicated, and which are consistent with international human rights norms and standards" (UN Secretary-General, 2004).

In developing countries rule of law estimates are weak as compared to developing countries. Table 1 shows rule of law estimates for four groups of countries according to the income-low, lower middle, upper-middle, and high-income countries; and also specifically for Pakistan. The table shows that most of the low, lower middle and some countries of the upper middle-income countries have negative estimates, which doesn't show a healthy picture of the rule of law. Table shows the various statistics for these groups of countries for rule of law. It can be seen that for the first three groups the statistics are not very healthy and averages are negative. However, as we compare the statistics across the groups, the numbers gradually improve, thereby declaring the high-income countries to have better rule of law estimates. Since, Pakistan is categorized in lower-middle income group by the World Bank, so we compared its rule of rule of law estimate within its own category also. Pakistan's score is far less than the average in its own category, which shows a low rule of law environment.

Table-1: Summary statistics for Rule of Law estimates for 1996-2018

\begin{tabular}{|l|c|c|c|c|c|}
\hline & Low & Lower Middle & Upper Middle & High & Pakistan \\
\hline Min & -2.61 & -2.01 & -2.18 & -0.19 & -0.97 \\
\hline Max & 0.10 & 1.04 & 1.41 & 2.10 & -0.63 \\
\hline Average & -0.98 & -0.60 & -0.26 & 1.12 & -0.83 \\
\hline Median & -0.96 & -0.64 & -0.33 & 1.10 & -0.84 \\
\hline
\end{tabular}

Source: World Bank

If we look closely at the legal system in developing countries, we will come across another system running along with a formal/official or governmental system known as informal or nongovernment legal system. The official system consists of courts that are stipulated by the law of the country and has the authority to decide on conflict brought in by any party (ies), and to implement their decisions through law-abiding citizens, police, or other sources. Outside the above official fora, there are other arrangements to which parties in a dispute can agree to get their disputes resolved. One of such arrangements is known as Alternative Dispute Resolution System (ADR). Usually, the law of most countries recognizes the agreements reached in the ADRs as it fulfills the two minimum criteria, i.e., agreement of all parties in a conflict and "not violating" the basic law of the country. Arbitration and mediation are two such examples of ADR (Fisher, 2017; Stone, 2004). Informal Justice System (IJS), are like official courts which claim to be competent to decide about conflicts of rights regardless of the consent of one party (or sometimes both parties). These are also referred as local courts, traditional or customary courts. Religious courts are also often categorized in the IJS (World Justice Project, n.d). IJS 
does not have the power to implement their decisions as official courts do, but they carry out the enforcement through social pressures and regional influences (Goff, 2016; Swenson, 2016). For example, in the case of a tribal system if someone does not accept the decision, he/she has the danger of being subject to social boycott or at extreme, face expulsion from the tribe. Similarly, as reported by Barfield (2006), in Afghanistan the Shura made the decisions in most of the informal system according to Shariah (Islamic law), which act as an extra reason along with social pressure for parties to accept and follow the decisions of the local courts (See, Kunesh, 2007).

While the literal meaning of IJS implies informality of the fora, many studies of IJS stress that IJS may exhibit some formalities and may even be more formal than the official courts. For example, Gacaca courts in Rwanda (post-genocide period), were based on pre-colonial customs of dispute resolution and thus used codified laws. These "traditional courts" were included in the definition of the formal justice system and, other times referred to as ADR (Corey \& Joireman, 2004). Similarly, Dalgleish (2005) reported that the system of cadi in Mali, which is based on the Quran, is more formalized than the state system. Jueces de paz in Peru are appointed by the state, but they are not expected or required to follow the state rules, so they are not considered to be a strict form of IJS. At the same time, IJS may be a severe threat to the official justice system in the sense that not only does the official law of the country lose power and thus many conflicts arise between several IJS within a country, but also human rights may be threatened. For example, Rathore (2015) and Kirmani (2000) described that women's rights according to the UN charter, are systematically ignored and violated in e.g. tribal areas of Pakistan and some parts of India (Rajan, 2003; Lyengar, 2007). To differentiate between the two-ADR and IJS, is sometimes hard as there are no strict lines that divide the two (Goff, 2016; Swenson, 2016).

The presence of the IJS, partially explains the lower score for rule of estimate for these countries. In this sense, this system seems to be undesirable and a threat to the official justice system. However, there is a need to understand this system more deeply and to assess its impact on dispute resolution and especially its contribution in the presence of a formal/official justice system. There is also a need to revisit the possible determinants of the existence and/or need for the informal system along with its merits and demerits. This paper is an attempt to understand the dynamics related to IJS within the context of developing countries, a country like Pakistan. A critical analysis helps to understand why this system emerges, why people feel shy of the formal system and select informal way of settling their disputes. This research suggests how to work with these systems in the short run and how to integrate them into the formal legal system. If it is not possible to entirely eliminate them, then how can these systems be improved and made acceptable as an alternative dispute resolution mechanism. We will not so much cover the IJS in general but will try to answer the above question from the perspective of the developing countries, taking Pakistan as a case study.

Given the existence of IJS, any government has two choices, either it can completely wipe out the IJS or to work with it as suggested by Chirayath et al. (2005). Therefore, in this para we present the strategy to approach IJS. We will adopt a qualitative approach to investigate our research questions. As suggested by Mack et al. (2005) qualitative methodology can help understand the psychology, values, opinions and behavior of specific group or clan. Since, the discussion is related to IJS, which essentially provide services and can be regarded as social institution, thus, use of qualitative methodology is more appropriate. Regarding qualitative approach, we mean that to find answers to our questions, we will try to review the literature 
written on the experience of other developing countries and try to justify the IJS and methods suggested to reform/approach them. In this regard we will also try to use some of the data that was collected not only for the other developing countries but for different sections of IJS (for example Jirgas and Panchayats). We also used the limited data, as quoted in various reports and case studies to determine the strength and weakness IJS to formulate an effective approach to engage informal system, to capitalize on strengths and minimize/weakness of IJS. We will follow a qualitative approach wherein extensive use of case studies and data will be made. We must admit beforehand that the data on the number of cases in IJS is greatly limited and there is no organization which collects the data on how many cases are dealt in IJS within Pakistan or in case of other countries. Therefore, we will resort by using data quoted in many different reports, magazines, and newspaper articles related to Pakistan in particular and where needed, related to other developing countries closely resemble to Pakistan. We expect the current study not only to inform policy makers but also will be helpful in how the judiciary can be tailored to take into account the informal legal system.

\section{Access to justice}

Access to justice can be defined as "the ability of people to seek and obtain a remedy through formal or informal institutions of justice, in conformity with human right standards" (Wojkowska, 2006). The access is important for various reasons like to give justice to the poor and disadvantaged (UNDP, 2004). It will bring more equity into society and will result in poverty reduction. Access to justice will also ensure fair democracy and conflict prevention, and is especially important for the poor because they are underprivileged and their financial inability makes them more vulnerable to crimes and illegal acts which can include human rights violations. This in-access to justice can indulge them in negative activities, for example taking revenge on their own and try to conduct justice as they deemed it appropriate. Of course, it can lead to chaos, lawlessness and instability in the society.

To access justice, applicants have mainly two choices. One is to take their complaints to the state institutions where formal laws are followed which were promulgated by the state, under which complaint will be decided accordingly. The alternative forums can be other than the state system usually called IJS. While defining the IJS, we must admit that there are no clear boundaries in literature among some of the legal systems, according to which they can be classified as informal, semi-informal, or formal. Faundez (2006) was of the view that boundaries that can be used to classify a particular system belonging to IJS are blurry. There are systems, which can be broadly categorized into IJS, but they have highly developed systems of rules and procedures on which they govern. Similarly, IJS may include a "traditional justice system", but not always, a traditional justice system is a part of IJS. For example, Gacaca courts in Rwanda (post-genocide period), were based on pre-colonial customs of dispute resolution, and thus used codified laws. These "traditional courts" were included in the formal justice system. It also can include various types of mediation, arbitration, on-line dispute resolution and many others.

Similarly, in addition to traditional courts, indigenous, customary, popular and restorative are few of the other examples, which sometimes are classified as IJS and other times outside the IJS. For instance, customary laws are sometimes regulated and recognized by the state where they are practiced and thus, can be classified as semi-formal. Swenson (2016) also pointed out that customary, indigenous or religion-based systems, as well as western-introduced mechanisms such as arbitration or paralegal programs that function separately from the formal 
system can be included in the informal system. However, as Dalgleish (2005) observed that the system of cadi in Mali, which is based on Muslims religious Book (Quran) is more formalized than the state system in the north. World Justice Project (n.d.)- includes many aspects in the informal justice system which includes "traditional, tribal, religious courts and communitybased systems for resolving disputes".

Therefore, there are no clear lines by which one can categorize a system as formal or informal, but this non-clarity does not undermine the fact that, this system exists around the world in one form or another, and is existing in a strong form inside most of the developing countries especially those grouped in the middle-income and lower-income countries. One of the main reasons can be the underdevelopment of these countries itself. Besides, Woolford and Ratner (2007) pointed out that characteristics of IJS tend to follow three principles which also result in their acceptance among people and their discourse from the official system. First, IJS tends to facilitate the parties in a conflict in terms of participation and empowerment without the help of legal aid like lawyers and law professionals. Second, the rules in IJS are flexible, unlike the case in the official system, which is bound by the rules and constitution. Third, the implementation does not require force or use of authority but rather it is based on and form the free consent of the parties who are involved in every step of their trial, which can better lead to their satisfaction.

\section{Role of informal justice system in accessing justice}

The importance of IJS in helping access to justice can be assessed from the fact that in some countries, according to UNDP (2004) and Schärf (2003), 80-90 percent of all disputes go through customary judicial processes. According to the same sources, Sierra Leone is another country where $85 \%$ of the population uses forums in IJS and even the Government recognizes the decisions made by such forums for a possible reevaluation or implementation. Around $80 \%$ of the total population in Sierra Leone is legally under the customary law as defined by the constitution. Under this customary law, there are special laws for a particular community (Chirayath et al., 2005). In the case of Bangladesh, an estimated 60-70\% of people prefer to go first to a Salish before contacting the formal judicial system. Schärf et al. (2002) showed, in Malawi $80-90 \%$ of all disputes are processed through the customary judicial process. Similarly. In Burundi $80 \%$ of the people consult Bashingantahe to settle their disputes (Thorne, 2005). The reality of IJS can be judged from the fact that Chief Justice Warren Burger in 1976 at Pound Conference discussed limitations of the judicial system related to delays, costs and complexity of the formal courts. He suggested that the cases of small litigants be sent to other channels for quick settlement. Other speakers also agreed with the Chief Justice and suggested to settle the disputes through alternative dispute resolution mechanisms. Sander (1985) proposed that courts should include "Dispute Resolution Centers". The applicant may come through these centers and if a case can be settled before it reaches a judge would help both the courts and complainants. Moreover, as suggested by Alam et al. (2020), Ullah and Bano (2020) and Mahmood et al. (2020), beside their role of providing alternative justice, these IJS can also provide other services like, social welfare to the marginalized people in specific areas.

The IJS often is mentioned in the news mainly because of the inhumane/controversial decisions it makes, some of which we discussed in earlier paragraphs. However, many good decisions are made by IJS, which do not make it up to the press, for example the settling of land disputes, family disagreements, local village problems, such as irrigation to land on turn-wise basis and inheritance cases. The service that IJS is providing to the people near their doorstep should not 
be over shadowed by its "bad" decisions. If the same cases (cases against which good decisions were made by IJS) were taken to official courts then the amount of time and cost would undermine the effectiveness of the outcome, with still no guarantee that the outcome will be satisfactory. In our view, a balanced view should be presented that also documents the positive side of IJS and to capitalize on the positive point and gradually improve on the negative aspects of this system.

IJS system is seen as a quick, near to home and a cheap way to get justice without involving costly lawyers and interpreting difficult laws. Some may argue that backing the informal system may weaken access to the formal system further (Nyamu-musembi, 2003). However, if there are no viable means other than the formal system, and this system is not able to resolve the disputes, then there may arise violence or further severity of the conflict, which is a highly undesirable outcome. Informal systems may prove to be a mean of resolving the conflict in many countries as Zitelmann (2006) pointed out that unresolved disputes especially over natural resources have resulted in social violence on a larger scale in parts of Maluku, Kalimantan, and Sulawesi in Indonesia during the post-reform era. In Colombia mob justice or lynching is five times greater than in communities where the formal justice system is not reachable and IJS is also not functional (Chirayath et al., 2005). Informal systems can be helpful in those regions, countries or societies, which have overcome a major conflict and the formal legal system has broken down or is just developing (for example Afghanistan and Syria). An interesting case in this regard is Afghanistan, where formal courts sometimes refer cases to the informal courts to resolve the matter. These courts also accept and record the decision of the informal courts for pending cases (Barfield, 2006).

\subsection{Strengths/determinants of informal justice system}

As Faundez (2006) and Amnesty International (2000) noted that in IJS there is a strong sense of the community involvement as a group. According to Faundez (2006), there is a strong presence of collective interest in the IJS setting. Decisions are made on a consultation basis, which creates strong indications of making harmony and reconciliation among the grieving parties. The arbitrators in the IJS are appointed from within the community that makes it more viable that parties will accept the decision. All of this makes IJS more "local" thereby reflecting local culture and social norms. The localization and same group members make IJS more understandable towards the conflict itself, and the acceptability of the solution/decision. It will raise the level of trust and social legitimacy for IJS. Solaas (2009) found that $94 \%$ of East Timorese trust in their traditional justice system (which is known as adat). In Indonesia, 69\% of the respondents believed that IJS fairly treats everyone in the society. This ratio drops to $28 \%$ in the case of a formal justice system. Only $15 \%$ were of the view that IJS will deal favourably with the rich and the powerful. However, this percentage rises to $50 \%$ when the same question was asked for formal courts. Summing up, according to the studies of Idris (2007), Saltman (1979), UNDP (2004), and Wojkowska (2006) we can identify some important determinants of the IJS as follows:

\subsubsection{Access to the formal justice system}

Everyone has the right to access the formal justice provided by the state. In reality this is often denied or for a number of reasons. For example, distance from the locality to the courts is a strong reason for people not to consult a formal system. They cannot travel or cannot spare time to travel to these courts on a daily basis. 


\subsubsection{Delays}

A dispute in a formal system may take considerable delays till it will be finally settled. These can be due to the technical reasons of the case itself or already a number of cases plunged up in the courts to be heard. In India there are 30 million cases pending till 2015, which is indicative of the backlog of cases and the apparent delays in the formal system. These delays frustrate the parties who will than resort to some alternate dispute mechanism and IJS can provide them with a platform where they can get quick justice and at the same time a negotiated solution.

\subsubsection{Complexity}

The formal court proceedings and the language used in its normal proceedings is highly technical and complex. As the literacy rate in developing countries is not so high, so there is a limitation on part of the individuals to understand the laws. In most countries, laws are written in a language other than used by most of its inhabitants. As Saltman (1979) noted that "when translations are required, the proceedings are usually long and turgid. Quite often the translations are hopelessly inaccurate and invariably they do not capture the nuances of the speaker's mother tongue".

\subsubsection{Cost}

It is generally agreed that a substantial cost is involved to fight a case in a formal court. Given the complexity above, and delays in the formal system this cost multiplies many folds that forces applicants to think twice before they are willing to take their case to formal courts. For example, as explained above, not every individual can understand the legal laws which force them to hire a lawyer who will fight the case on their behalf. This lawyer usually charges a fee for his services which will definitely increase as the length of the case will prolong. A survey by Wojkowska (2006), found that most people are reluctant to consult the formal courts because of the case processing fees as compared to what is at stake. Moreover, people also calculate their opportunity cost whenever they decide to consult a formal court. For example, if a child mother in Zimbabwe has to claim roughly $\$ 25$ round trip, so she will be less motivated to take her application to a formal court. Similarly delaying tactics by the defendant's lawyer also increases the cost of the claim and ultimately she may end up paying more for her trips rather than what she is claiming in lieu of maintenance.

\subsubsection{Corruption}

Corruption in the formal legal system is another reason for applicants resorting to informal justice forums. In this context generally not only the applicants but people in general, view the legal institutions as corrupt. For example a study for Pakistan carried out by Shinwari (2015) showed that almost $47 \%$ of the total people surveyed believed that legal institutions are corrupt. An interesting finding was that $82 \%$ of the people viewed Police to be corrupt. This was significant in the background where Police have to file the first investigation report and to carry out investigations. Since 2013 more people believed this to be true both for the case of Police and judiciary. The number increases from $35 \%$ to $47 \%$ for judiciary and remains stable at around $88 \%$ for the case of Police. In India, $69 \%$ of the total people surveyed had to pay a bribe to a police officer(s) to get their complaint to reach some conclusion stage (whether this 
complaint was rightful or not). For Pakistan, it was $74 \%$, which validated the view of the corrupt Police system. $49 \%$ of the total surveyed people in Bangladesh have to bribe Police for the same reasons.

\subsubsection{Foreign laws in a domestic setting}

There may be a case where the legal system (all of it or some of it) may be imported from outside the country/society, which may become susceptible/unacceptable to the locals. For example, many tribes in Africa as well as the USA still follow their own law and consider the country's law to be alien. This is more evident in countries that were colonized in the past. In the Sub-continent, when the British floated their law it was considered to be a foreign law and in the beginning it was resisted and many disobedience movements were launched.

\subsection{Weaknesses in informal justice system}

The IJS are having their shortcomings as well. The first and foremost is that its existence directly threatens the official justice system and thus writ of the government. While IJS can deliver in homogenous communities/cultures but when it comes to heterogeneous communities, IJS fails to deliver the required output (Kötter, 2015). In other words, IJS may be effective within a community but when it comes to a conflict across groups/communities IJS is not a suitable forum even having its community-based conflict resolving system. Another notable critique on the IJS is male dominance and violation of human rights. Stephens (n.d.) showed for the case of Pakistan and Afghanistan the tradition of Swara which means to give away a girl or woman as slave/wife to others as compensation for the killing of a member of the family. Patel 2008 showed the existence of karo-kari a form of honor killing in rural and tribal areas in Sindh province. Similarly, the National Commission on the status of women in 2016 in its report mentioned that a Jirga in Diamir district (KPK) declared that women are not allowed to vote in elections. In the same report, a Jirga in Northwest Pakistan forced a minor girl (11 years of age) to marry a man aged 44 as compensation for the rape offense did by her uncle. Ironically as mentioned by Mahmood (1994), if later on it is found that the woman who was killed or given away in name of honor was innocent, still there are no convictions or compensations based on mutual agreements. IJS is mainly nominated as oppressor of women rights in general (Ullah, 2018).

As IJS is informal so there is no "strict" check and balance system in this process. It has already been explained that social pressure and public participation may ensure a fair outcome, but at the same time it can result in an unequal outcome. This social pressure might be due to age factor, gender, or economic status. Also, because the arbitrators are from the clan itself and they might have their "friends or loyalty" so there is always a chance that arbitrators will favor one party in a resolution of a dispute. This favor may also be subject to retain their position of power in a society or clan. For instance, Golub (2003) noted that in Bangladesh the Salish is influenced by at least three parties. The elected officials of the Union, village elders and the religious clergies known as Mullahs. The Mullahs, with their fatwas (a ruling supposed to be based on some scripture), elected officials with their state power and the village elders, using their influence sometimes result in a favorable decision to one of the parties in a conflict. Similarly, Zitelmann (2006) for the case of Musyawarah in Indonesia observed that a relatively weaker party in a dispute is sometimes forced to accept the decision which favors the powerful party. In another situation weaker parties can be forced to accept a decision to preserve harmony in a society or to protect the others from a powerful (Roberts, 2004), This situation is 
more prevalent when one of the parties is a woman or from a minority. According to a report by the Center for Humanitarian Dialogue, a woman in Somalia is often seen to be directed by IJS to marry her attacker (rapist). The analogy behind this kind of decision is to establish peace among/across the clan or tribe. This is fulfilled by forcing the attacker's clan to pay a full dowry to the victim's clan. This bond of marriage also solidifies the relationship between the two clans beside man and woman thereby establishing the honor of a woman. But this decision clearly violates the woman's right to getting her attacker punished (LeSage, 2005). Another disadvantage is that, although its proceedings are carried out in public and there is large participation, however, IJS has no accountability. This also means in turn that the right of appeal, which is integral to a formal system, may not be present in IJS. Therefore, the fairness of the system or decision heavily depends on the person or group of persons conducting this process of hearing the arguments.

A major shortcoming of the IJS is that as the societies are getting modern and crimes and disputes getting more complex, IJS may not have the abilities and skills to correctly determine the nature of crime or dispute. This is because the arbitrators are usually selected based on of age and experience and the old experience might not be very helpful in understanding a complex situation. For example, in Somalia Xeer cannot determine the boundaries between the cities and the clans, because this boundary is non-existent and blurry. Similarly, arbitrators may not know about modern economics and the rules regarding private property. It is even more evident where the arbitrators are usually the religious leaders who usually are expert in matters related to religion, but do not qualify to know modern private and property laws. Last but not the least is that we should never expect that the elders/leaders/adjudicators in the IJS are fair and not corrupted. The Meerwala case in Pakistan is a prime example of such a corrupted decision Rehman, 2002). In this case, the jirga passed an order to rape a young girl for the crime did by her brother. This case later became famous as the Mukhtara Mai case taken up by the official courts. Originally there were 14 accused but later on when the case was heard by the Supreme Court of Pakistan, most of them were acquitted. This was a shock to human rights observers and civil society, which also shows weaknesses in the official system in Pakistan (Bhatti, 2019). An encouraging fact in the whole episode was that a local imam was the first to bring up this case and condemn it after the Jirga made its decision, which showed that this case has nothing to do with what is called religious justice.

\subsection{Proposed strategies to engage informal justice system}

In a report by Shinwari (2015), people were asked the question: will they support the IJS if it is recognized by the state, $45 \%$ agreed and $25 \%$ did not agreed. Interestingly $40 \%$ of the respondents were of the view that if the IJS is integrated with the official system, then the spirit of the IJS would be lost and it will be plagued with the same weaknesses present in the official justice system. In the same report out of 440 litigants who brought their cases to the official system, $42 \%$ were dissatisfied with the outcome and they showed an unwillingness to bring their cases in the future to the official justice system and would like to prefer ADRs. Another $39.5 \%$ of litigants showed frustration with the official system and they would not come to the official courts if an ADR was available to them. Thus, in total $81.5 \%$ of the total interviewed were discontent from the official system. Interestingly among those who have not been to any system, $53.3 \%$ of the respondents said that they would take their cases to Police and only $13 \%$ were willing to consult IJS or ADR. It shows the confidence of people on the official courts, but earlier statistics showed that once they consult the official system, their degree of satisfaction and trust decreases. In contrast, when the people in the Pashtun and Balochistan 
tribal areas were asked the same questions $47.8 \%$ said they would consult local jirga for settling their disputes. When asked about the effectiveness of the many IJS and official courts, $41.2 \%$ of the respondents termed IJS to be more effective, whereas $80 \%$ declared local IJS in form of a clan or extended family to be more effective. In addition, $33.6 \%$ of the poor showed trust in IJS which is not surprising as IJS is considered to be much cheaper, accessible and quicker as compared to the official system (Round-table discussions in Lahore, Karachi and Quetta, August - December 2013). Another interesting question in the survey was that if the state should recognize the IJS, $44.5 \%$ of respondents agreed to it while $24.9 \%$ did not favour it. However, a significant percentage was of the opinion that state/courts should decide about the type of case which IJS can hear and decide. An encouraging outcome was that $58.2 \%$ of the respondents favour women's participation/representation on IJS forums.

The above statistics show substantial support for IJS and therefore abolishing it will not be of great help as the system will continue in the shadows. There is a need to reform or engage the informal system as was also suggested by Mahmood et al. (2018). In order to engage the IJS, the literature suggested three approaches (Nyamu-Musembi, 2003; Thorne, 2005). The first calls for reforming the IJS by updating the forum with women's rights, basic human rights and following the basic minimum law of the country. The second calls for regulating the IJS in a multidimensional way, for example the state deciding about the kind/types of case an IJS can hear and defining the decisions it can reach on those case. The third (that we also recommend) is the gradual phasing out of the IJS and replacing it by ADRs.

We suggest however, to reform IJS, it needs careful analysis of their role within their regional and social area of activity. We believe that there is no one-size-fit-all model for reforming IJS and there might be a need to devise multiple strategies, specific for each type of IJS existing in a country. Besides, the legitimacy of IJS should be dealt very carefully, as the official legal system derives its legitimacy from national institutions, while IJS do not enjoy such backing. So, an inclusive process should be initiated with the local communities inducing them to accept adherence at least to some basic laws. As Mahmood et al. (2018) suggested to reform IJS, we also recommend to engage and to bring in reforms in IJS. However, to reform IJS, we suggest that it needs careful analysis as to its role within an area/group. We believe that to reform IJS there is not just a one-size-fit-all model and there might need to devise multiple strategies for each type of IJS existing in a country. Besides, the legitimacy of IJS should be dealt carefully as relative to the official legal system, which derives its legitimacy from national institutions, the IJS does not enjoy such backing. So, an inclusive process should be imitated with the local communities where they should accept to adhere to some basic laws. A good example of such an arrangement is South Africa where the government since the independence was faced with the question of what to do with customary courts. There were calls to abolish them altogether based on the views that all citizens should (and do) have equal rights and must face the same justice standards. In a long and still ongoing legislative procedure over the last two decades, the South-African legislator has proceeded towards a Traditional Courts Bill that observes the heterogeneity of community laws and their acceptance throughout the country and, most importantly, guarantees the constitutional rights of all parties involved in traditional court procedures (Republic of South Africa, 2017). From the very beginning of this legislative process, proponents of the Bill aimed at supporting and nurturing the traditional justice system prevailing in South Africa (Rautenbach, 2012; Scharf, 2003).

To get a glimpse of the extent of regulation of the Act, it is worthwhile to quote its Section 2. The objectives of this Act are to: (a) affirm the values of the traditional justice system, based 
on restorative justice and reconciliation and to align them with the Constitution; [...] (c) create a uniform legislative framework, regulating the role and functions of the institution of traditional leadership in the administration of justice, in accordance with constitutional imperatives and values; and (d) enhance the effectiveness, efficiency and integrity of the traditional justice system." While these fundamental objectives remained more or less unchanged during the many steps of legislation - which included complete restarts - its safeguards for constitutional rights and against any form of discrimination have burgeoned. The Bill also clearly restricts the traditional courts' competences to dispute resolution by "restorative justice", which in terms of the Bill includes a wide range of court orders ranging from simple indemnification to orders to "attend any form of training, orientation or rehabilitation" but clearly excludes any form of criminal punishment. Together, these safeguards for rights and restrictions of competences have high potential to resolve the conflict between the supremacy of informal justice systems with respect to their accessibility and their inferiority with respect to modern human and constitutional rights.

Another strategy to engage the IJS was suggested by Thorne (2005), who argued that government and donor agencies should interact with IJS to rectify their shortcomings with regard to their procedure and decision making process/quality. According to the author, these shortcomings are the main motivation for the formal system, and NGOs to engage them and to help them remove these shortcomings. Wojkowska (2006) was also of the view that reforms should be introduced in the IJS and let the system work itself. Wojkowska also wrote that ignoring the system would not help remove its shortcoming and with the passage of time these shortcomings might become "norm" of the system itself which is undesirable. She emphasized to take advantage of the IJS by keeping it outsourced but to engage them only for reforms. Latigo (2008) also supported this view that IJS cannot be termed as a success and be declared as complete failure. Latigo, rather emphasized that the positive traits of the IJS be accepted and to work on the negatives of the IJS. At the same time, he strongly believed that IJS can complement a formal justice system but itself cannot provide solutions to all problems. After this consultation some of the basic laws can be written or codified according to which IJS are free to make decisions at the local or community level. The only difficulty is to find some substitutes for the written codes that may be accepted to different communities. Another thing that must be taken care of is that these written codes be updated from time to time to streamline the process, especially in the case of customary laws, as they are not fixed and change over time. We are aware that this suggestion is not simple as there may be some "rigid" practices that existed from time immemorial. With these codes it is hard to eradicate these practices in the short run. The basic aim should be the protection and well-being of the victim.

The analysis shows that the IJS is required to follow a minimum set of rules that would adhere to the state rules. Only then can they be accepted as a forum where the decisions are acceptable to be implemented or reconsidered in the official justice system. A good example of such an arrangement is Kebele Social courts in Ethiopia, which apply a traditional method of arbitration called Shimglina. Another example is the Pakistan FATA/PATA region of which Jirga system was recognized in past. The jirgas are free to make decisions with minimal intervention of the state according to the tribal own cultural values and religious beliefs. However, the parties in the conflict have a right of appeal and, while complete abolishment of group punishment must be the ultimate goal, at least it was agreed that children under the age of 16 and women will be excluded from any sort of group punishment. According to many authors, it was not enough but all agree that it was a step in the right direction. Another case worth mentioning and to be analyzed is the case of Bolivia where Plurinational legal state was introduced into the 
constitution. It formally gave recognition to the IJS in the form of traditional courts and customary courts. Local tribes-which were practicing their own legal system-can have the backing of the state on several social matters related to their own tribal people. The procedure of the customary court was modified and now they were asked to record every case and to provide to the state or official system if required. It is worth mentioning that a young political leader who was in favor of the indigenous self-governance style of administration put the above recognition forward. Similar forms of structures were followed in Latin American countries as well and for other countries that are trying to deal with the IJS in their own countries.

Another form of IJS was introduced at the local community level in Pakistan by the Local Government Ordinance, which formally recognized Musalihat Anjumans (MA) or Reconciliation Committees. These committees were comprised of non-elected members, supposedly of good repute and integrity, selected through Insaaf committees at the level of union council and were granted the formal power of deciding disputes between members of the local community. The MA usually listened to parties in conflict and through their linkages in the local administration and Police tried to solve the conflict before it reached the official court. It is most noteworthy that under Section 104 of the Local Government Ordinance, the formal courts could refer any case to the MA to induce a pre-trial settlement of the parties before the MA (Zafar, n.d.). The Local Government Ordinance was repealed in 2011 after only ten years, but still it seems attractive to us to engage traditional courts as a compulsory and to some degree formal pre-trial settlement stage in the legal court procedure and thus alleviate many disputing parties from unnecessary burdens connected to the formal justice system.

Sometimes a top-down approach is also advantageous as it would likely be more beneficial. The arbitrators can be educated about the rights and their significance in context to the formal sector as well as internationally. This would put pressure on them to make decisions in accordance with these rights, for otherwise, a formal court can overturn the decision or the matter can be reported in the national press, which can damage the arbitrator's reputation. As to the arbitrators, some authors suggested that the arbitrators at the community level should be appointed by the state. But in our view this will backfire the process because people would be seeing them as an alien for the community. Our strategy would be to include at least one person who will monitor the whole process and at best only give his expert advice or, in other words, tell the local arbitrators the position according to the formal law system. In this regard, a system carried on by an NGO would be most helpful. We thus recommend educating the arbitrators about as many aspects of the decision-making process as appropriate.

\section{Role of informal justice system in Pakistan}

As mentioned above, IJS is not a recognized system in Pakistan. However, it exists by and large along with the official system. The main reason why it exists is the failures in the official system besides the number of factors related to history, local customs, and/or culture. IJS is seen as a quick, near to home, and cheap way to get justice without involving costly lawyers and interpreting difficult laws. As Idris (2007) pointed out that a Panchayat can be called quickly in just hours' notice with minimum expenses and there is no need to reserve a place to convene its meeting as it can be held under a tree even after the working hours. The parties in a conflict can give their "uncorrupted and non-tailored" view to the administrators (elders) and they do not have to hire expensive lawyers or pay the court fees.

If we look in history, Pakistan inherited its legal system from Britain but the informal system 
existed before the British's came into the subcontinent. The Colonists of sub-continent tried to adopt an indirect style of rule through feudal lords and tribal chiefs (Inam et al., 2020). The chiefs of a clan were permitted to decide about the conflict relating to their people and thus giving them local controls. However, the decisions of the tribal chief can be overruled by a local representative of the British government serving as a Political Agent or Deputy Commissioner (Baras, 2004). This practice gave justice system practically in the hands of local chiefs or tribal judiciary. It gave rise to the powerful role of bureaucracy, which till date exists, in the sub-continent. According to Okafo (2016), people in Pakistan still generally believe in IJS for settling their disputes which are derived from rural culture and practices. Over time, the belief of the people and strengthening of these IJS speaks itself for the effectiveness of the informal system. For that reason, given this history, there are many different IJS working in Pakistan like Panchayat in Punjab, jirga in Khyber Pakhtunkhwa and Pashto speaking part of Balochistan, and Baloch jirga in Balochistan. Mainly, the tribal chiefs or local leaders are heads of these IJS but mostly elders from the same society or area govern it. These elders may include persons with special expertise and in case a conflict requires special treatment or investigation experts from other fields can be hired to assist them. However, as to their operation each system has its unique way of dealing with the conflicts mainly drawn from religion, culture and local customs. Small matters are dealt by with few individuals but major cases (like criminal) are dealt carefully and normally the community at large is involved. IJS is not formally recognized law in Pakistan with the exception of erstwhile FATA and PATA. The rule by a tribal chief, commonly known as "Sardari" system was demolished through the Sardari Abolition Act of 1976. The constitution guarantees several rights for all citizens and any law or custom that negates these rights stands void (Idris, 2007; Amnesty International, 2002).

The major areas where the IJS concentrates in Pakistan can be divided into three major parts. The first part is that of Sindh (mainly rural areas), the second is Pashtun areas of Khyber Pakhtunkhwa and Balochistan (See Mahmood et al., 2018) and third is the central Punjab. A typical IJS forum whether it is called jirga or Panchayat or Failso in Sindh work in almost the same manner. As Waheed et al. (2009) noted that normally it is convened in a common room some time called Autaq or hujra (it is usually a tribal/group leader's place of residence or an area designated by the community to meet up regularly). The place is considered to be having sanctity and every member of the society/group respects this place). The two parties put up their case and explain their side of the story. In some cases, the parties to the conflict have their advisors or negotiators who discuss and try to build support for their side. Sometimes the above advisors also act as mediators and try to diffuse the situation with no or minimum penalty/punishment. However, unlike lawyers, they do not charge anything from the applicants and they just do it out of brotherhood or being members of the same group or their closeness with the applicants. The role of these advisors become crucial if both or one of the party is a woman. In this case, women may or may not be invited to the jirga and their views are explained through advisors.

The elders of the tribe presiding over the jirga listen both of the parties and their advisors and if necessary they can hire/appoint an expert within the tribe or outside the tribe to get an expert opinion. After this, they will meet again in the absence of applicants (however, their advisors may or may not be present) and they will reach at some decisions keeping in mind the history of the applicants, the nature of the case if decided in the past and any other related information. The decisions will then be communicated to the parties to be implemented. Sometimes the decisions can be in the form of more than one option and parties in the conflict are allowed to accept one of them. The applicants then have social pressure from their advisors and group 
members to accept the decisions reached by jirga and to implement it as well (Mahmood et al., 2018). An interesting practice during the trial/hearing is the use of oath to get the truth out of the parties. For example in jirgas, normally the oath is to be taken on the Holy Book by the both parties. To some instances, the party has to take an oath in the name of his wife to make believe to Jirga that he is speaking truth. In some parts of Sindh and central Punjab the Chalbehli or Bar behli-to walk on the hot coals to prove the same (Amnesty International, 2002). Such practices add to the negative image of IJS.

Pakistan is a developing country and even after coming into existence 70 years ago, the legal system is still struggling to take its root. Access to justice is guaranteed in Article 4 and under Article 10-A of the constitution. However, the World Justice Project (n.d.) report on the rule of law ranked Pakistan's criminal justice system at 98 out of 128 countries in 2020 which is a decline from its $81^{\text {st }}$ rank out of 113 countries in 2016. In the same report the civil justice system was ranked even worse i.e., at 118 out of 128 countries, which also is a decline from its position relative to 2016, which then stood at 106 out of 113 countries. The overall score in the region is $5^{\text {th }}$ out of a total 6 which shows a low score for Pakistan. Its average is 0.39 as compared to the regional average of 0.45-as compared to India, Afghanistan, Bangladesh, Sri Lanka and Nepal. According to International Finance Corporations (IFC) in its report (Andhini, 2010), Pakistan is ranked 128 in the enforcement of contracts. On average it requires 3.5 years or 1261 days to enforce a simple contract. This is higher than in other countries in the South Asian region. According to different newspaper reports, at least 2 million cases are pending in superior and lower judiciary.

\section{Conclusion}

IJS exist in almost all countries belonging to different income levels, however their concentration and area of influence is largely present in least and middle-income countries. As some authors argued that IJS is undesirable and a threat to the formal justice system which should be eradicated. We found that in the short run, we cannot just put to an end to IJS because this is a system being run and managed by people, and it would not be suggestible to go against it, provided that some form of "justice" is being delivered by them at a nominal cost, near to their home and without much complexity. Given the income of the people and access to formal justice, corruption, delays, complexity and non-acceptance of the formal legal system itself motivate an applicant not to file a complaint in formal courts, we suggest that IJS should be engaged but at the same time legal awareness should be spread among the people not only about IJS but also about the formal legal system. This engagement would help policy makers to better understand the aspirations of the people, justifications of various customs and decisions by the IJS. We further suggest that some sort of training be imparted to the arbitrators in the IJS and they should be held accountable in some form, forcing them to follow at least the most fundamental substantive rules of the formal legal system for example human rights. The judgements of these informal courts should be subject to revision by the state justice system and be overruled if found in difference from some set standard rules. We conclude that IJS has its own advantages on which we should capitalize, and one should focus on eradicating their negative characteristics. Thus, by reforming the IJS on its negative aspects, IJS can play their role as a supplement to the formal or official justice system. 


\section{References:}

Alam, F., Ahmad, S., \& Bano, A. (2020). Jirga and Dispensation of Social Welfare Services: A Case Study of Mohmand Tribal District, Liberal Arts and Social Sciences International Journal (LASSIJ), 231-241. https://doi.org/10.47264/idea.lassij/4.1.20

Andhini, N. F. (2010). Doing Business 2010 (Doing Business). The World Bank. http://elibrary.worldbank.org/doi/book/10.1596/978-0-8213-7961-5

Barfield, T. (2006). Informal Dispute Resolution and the Formal Legal System in Contemporary Northern Afghanistan Thomas Barfield.

Baras, A. (2004). The mechanics of honor in Pakistan. Asian Human Rights Commission, 3(5), 2.

Bhatti, H. (2019, March 6). Mukhtar Mai rape case: SC adjourns review petition after suspects show up without legal counsel. Dawn. https://www.dawn.com/news/1467962

Chirayath, L., Sage, C., \& Woolcock, M. (2005). Customary Law and Policy Reform: Engaging with the Plurality of Justice Systems. Background Paper for the World Development Report, 1-31. https://openknowledge.worldbank.org/handle/10986/9075

Corey, A., \& Joireman, S. F. (2004). Retributive justice: The Gacaca courts in Rwanda. African Affairs, 103(410), 73-89.

Dalgleish, D. (2005). Pre-colonial criminal justice in West Africa: Eurocentric thought versus Africentric evidence. African Journal of Criminology \& Justice Studies, 1(1), 55-69. http://citeseerx.ist.psu.edu/viewdoc/download?doi=10.1.1.576.4708\&rep=rep1\&typ $\mathrm{e}=\mathrm{pdf}$

Esfahani, H. S., \& Ramirez, M. T. (2003). Institutions, infrastructure, and economic growth. Journal of Development Economics, 70(2), 443-477.

Faundez, J. (2006). Should Justice Reform Projects Take Non-State Justice Systems Seriously? Perspectives from Latin America. In The World Bank Legal Review: Law, Equity, and Development 2, 113-140.

Fisher, T. (2017). Law and Economics of Alternative Dispute Resolution. In F. Parisi (Ed.), The Oxford Handbook of Law and Economics. Volume 3: Public Law and Legal Institutions 1, 337-350. Oxford University.

Goff, D. (2016, December). "Working with Informal Justice: Key considerations for confident engagement." Knowledge Platform Security and Rule of Law, La Haye.

Golub, S. (2003). Non-state justice systems in Bangladesh and the Philippines. United Kingdom Department of International Development. http://siteresources.worldbank.org/INTJUSFORPOOR/Resources/GolubNonStateJu sticeSystems.pdf

Idris, I. (2007). Alternative Dispute Resolution: The Informal Justice Sector in Pakistan. LEAD Pakistan. http://www.lead.org.pk/lead/Publications/21\%20ALTERNATIVE\%20DISPUTE\%20RESOLUTION\%20The\%20Informal\%20J ustice\%20Sector\%20in\%20Pakistan.pdf

Inam, U., Nawaz, A., \& Andama, G. (2020). Colonization and Decolonization of the Indian Subcontinent; A Colonial Discourse Discourse Analysis of A God in Every Stone. Liberal Arts and Social Sciences International Journal (LASSIJ), 4(1), 282-292. https://doi.org/10.47264/idea.lassij/4.1.24

Amnesty International. (2002, July). Pakistan: The tribal justice system. Amnesty International Report. https://www.amnesty.org/en/documents/ASA33/024/2002/en/ 
Kirmani, N. (2000). Women's Rights as Human Rights: The Case of Pakistan. Senior Thesis Projects, 1993-2002, 47. http://trace.tennessee.edu/utk_interstp2/47

Kötter, M. (2015). Non-State Justice Institutions: A Matter of Fact and a Matter of Legislation. Non-State Justice Institutions and the Law, 155-187.

Kunesh, P. H. (2007). Banishment as Cultural Justice in Contemporary Tribal legal Systems. New Mexico Law Review, 37(1), 85-145. https://papers.ssrn.com/abstract=1080047

LeSage, A. (2005). Stateless Justice in Somalia: Formal and Informal Rule of Law Initiatives.

Mack, N., Woodsong, C., Kathleen, M., Greg, G., \& Namey, E. (2005). Qualitative Research Methods: A data Collector's Field Guide. Family Health International 36(10). https://www.fhi360.org/sites/default/files/media/documents/Qualitative Research Methods - A Data Collector's Field Guide.pdf

Mahmood, A. S. (1994). Sardari, jirga \& local government systems in Balochistan. Edara-eTadrees.

Mahmood, A., Ullah, S., \& Ashfaq, S. (2018). The Evolution of Jirga System: A Conflict Resolution Mechanism in FATA. Liberal Arts and Social Sciences International Journal, 2(1), 21-28.

Nyamu-Musembi, C. (2003). Review of experience in engaging with 'non-state' justice systems in East Africa. In: Commissioned by Governance Division, DFID (UK).

Okafo, N. (2016). Reconstructing Law and Justice in a Postcolony (First). Routledge.

Rajan, N. B. and A. (2003). Private Concerns in Public Discourse: Women-Initiated Community Responses to Domestic Violence. Economic and Political Weekly, $38(17), 1658-1664$.

Rathore, M. A. (2015). Women's Rights in Pakistan: The Zina Ordinance \& the Need for Reform (No. 38).

Rautenbach, C. (2012). South Africa: Recognition of traditional courts - loose ties between two judicial systems. Decision Making on Pluralist Normative Ground: On the Governance of Disparate Traditional, Religious and Statutory Laws in Pluralist Societies.

Rehman. I. A. (2002, August). Dark Justice. Newsline. https://newslinemagazine.com/magazine/dark-justice/

Roberts, D. (2004). Justice for the poor program: research paper on community access to justice and village judicial autonomy: second interim report. In agris.fao.org. http://agris.fao.org/agris-search/search.do?recordID=US2012413181

Republic of South Africa. (2017). Select Committees Amendments to Traditional Courts Bill. Parliamentary Monitoring Group. https://pmg.org.za/bill/680/?via=homepage-card

Saltman, J. (1979). Housing Discrimination: Policy Research, Methods and Results. The ANNALS of the American Academy of Political and Social Science, 441(1), 186-196.

Sander, F. E. A. (1985). Alternative methods of dispute resolution: An overview. University of Florida Law Review, 37. https://heinonline.org/HOL/LandingPage?handle=hein.journals/uflr37\&div=9\&id= \&page $=$

Schärf, W. (2003). Non-State Justice Systems in Southern Africa : How should Governments Respond? (Working with Non-State Justice Systems).

Schärf, W., Banda, C., Röntsch, R., Kaunda, D., \& Shapiro, R. (2002). Access to Justice for the Poor of Malawi? An Appraisal of Access to Justice Provided to the Poor of Malawi by the Lower Courts and the Customary Justice Forums.

Shinwari, N. A. (2015). Understanding the Informal Justice System: Opportunities and Possibilities for Legal Pluralism in Pakistan. http://www.camp.org.pk/wp- 
content/uploads/2016/03/UnderstandingtheInformalJusticeSystem.pdf

Solaas, I. M. (2009). Traditional justice in East Taimor: A Case Study of Justice versus Reconcilitation and its Consequences. Master's Thesis in Peace and Conflict Studies, University of Oslo. https://core.ac.uk/download/pdf/30799852.pdf

Stephens, M. (n.d.). Typologies, Risks and Benefits of Interaction Between State and NonState Justice Systems. Conference Packet for the United States Institute of Peace, George Washington University and World Bank Conference on Customary Justice and Legal Pluralism in Post-Conflict and Fragile Societies.

Stone, K. V. W. (2004). Alternative Dispute Resolution (No. 04-30; Public Law \& Legal Theory Research Paper Series). https://papers.ssrn.com/sol3/papers.cfm?abstract id=631346

Latigo, J. O. (2008) Northern Uganda: tradition-based practices in the Acholi region. In: Huyse L, Salter M (eds) Traditional justice and reconciliation after violent conflict: learning from African experiences. International Institute for Democracy and Electoral Assistance, Stockholm.

Lyengar, S. (2007). The Interface between formal and informal systems of justice: a study of Nari Adalats and caste Panchayats in Gujarat state, India. UNDP, Towards Inclusive Governance: Prompting the Participation of Disadvataged Groups in AsiaPacific, 103.

Swenson, G. (2016). Understanding and engaging informal justice. http://openaccess.city.ac.uk/1189/

Thorne, K. (2005). Rule of Law through imperfect bodies? The informal justice systems of Burundi and Somalia. Peace and Justice Conference. http://dspace.cigilibrary.org/jspui/handle/123456789/30866

Ullah, J., \& Bano, A. (2020). Militancy and Pashtun Culture: Challenges and Developments in Pashtun Society in Khyber Pakhtunkhwa, Pakistan. Liberal Arts and Social Sciences International Journal, 3(2), 115-127.

Ullah, R. (2018). Socio-Cultural and Economic Factors Affecting Women Political Participation in Dir District of Khyber Pakhtunkhwa. The Women - Annual Research Journal of Gender Studies, 10(10), 26-41.

UNDP. (2004). Access to justice. Practice note.

UN Secretary General. (2004). The rule of law and transitional justice in conflict and postconflict societies: report of the Secretary-General. United Nations Digital Library. https://digitallibrary.un.org/record/527647? ln=en

Vile, M. J. (1967). The Seperation of Powers. In J. R. Greene, J. P. and Pole (Ed.), A Companion to the American Revolution (2008) (p. 796). John Wiley \& Sons..

Waheed, A., Nadeem, A., \& Khurram, A. J. (2009). Proceedings 2. Second CBRC, 1-8.

Wojkowska, E. (2006). Doing Justice: How informal justice systems can contribute. Oslo, United Nations, December. http://ru.unrol.org/files/UNDP DoingJusticeEwaWojkowska130307.pdf\%5Cnhttp://siteresources.worldbank.org/IN TLAWJUSTINST/Resources/EwaWojkowska.pdf

World Justice Project. (n.d). World Justice Project Factor 9. https://worldjusticeproject.org/our-work/wjp-rule-law-index/wjp-rule-law-index2017\%E2\%80\%932018/factors-rule-law/informal-justice-factor-9

Woolford, A., \& Ratner, R. S. (2008). Informal reckonings: Conflict resolution in mediation, restorative justice, and reparations. Routledge.

Zafar, I. (n.d.). The Implementation Strategy for Successful Functioning of Musalihat Anjuman. 